\title{
A cell-free framework for rapid biosynthetic pathway prototyping and enzyme discovery
}

\author{
Ashty S. Karim ${ }^{\mathrm{a}, \mathrm{b}}$ and Michael C. Jewett ${ }^{\mathrm{a}, \mathrm{b}, \mathrm{c}, \mathrm{d}^{*}}$
}

${ }^{a}$ Department of Chemical and Biological Engineering, ${ }^{b}$ Chemistry of Life Processes Institute, Northwestern University, Evanston, IL 60208, USA

${ }^{c}$ Robert H. Lurie Comprehensive Cancer Center, dSimpson Querrey Institute, Northwestern University, Chicago, IL 60611, USA

${ }^{*}$ Correspondence: Michael C. Jewett, Department of Chemical and Biological Engineering, Northwestern University, Evanston, IL 60208, USA

E-mail address: m-jewett@northwestern.edu

Tel: 1847467 5007; Fax: 18474913728

Postal Address for all authors:

2145 Sheridan Road, Tech E-136

Evanston, IL 60208, USA 


\section{Abstract}

Speeding up design-build-test (DBT) cycles is a fundamental challenge facing biochemical engineering. To address this challenge, we report a new cell-free protein synthesis driven metabolic engineering (CFPS-ME) framework for rapid biosynthetic pathway prototyping. In our framework, cell-free cocktails for synthesizing target small molecules are assembled in a mix-and-match fashion from crude cell lysates either containing selectively enriched pathway enzymes from heterologous overexpression or directly producing pathway enzymes in lysates by CFPS. As a model, we apply our approach to $n$-butanol biosynthesis showing that Escherichia coli lysates support a highly active 17 -step CoA-dependent $n$-butanol pathway in vitro. The elevated degree of flexibility in the cell-free environment allows us to manipulate physiochemical conditions, access enzymatic nodes, discover new enzymes, and prototype enzyme sets with linear DNA templates to study pathway performance. We anticipate that CFPS-ME will facilitate efforts to define, manipulate, and understand metabolic pathways for accelerated DBT cycles without the need to reengineer organisms.

\section{Keywords}

Cell-free protein synthesis (CFPS), cell-free metabolic engineering (CFME), biosynthetic pathways, design-build-test (DBT), synthetic biology, $n$-butanol 


\section{Introduction}

For decades scientists and engineers have turned to engineering biological systems to help meet societal needs in energy, medicine, materials, and more ${ }^{1-4}$. This has been an attractive, sustainable way to produce small molecules, especially when chemical synthesis is untenable ${ }^{5,6}$. The ability to harness organisms that naturally produce molecules of interest has expanded the available chemical palate ${ }^{7,8}$. Often when natural producers are insufficient for production at the optimal titer $\left(\mathrm{g} \mathrm{l}^{-1}\right)$, yield, or volumetric productivity $\left(\mathrm{g} \mathrm{l}^{-1} \mathrm{~h}^{-1}\right)$, engineers seek to design biosynthetic pathways and regulatory processes in cells to meet certain manufacturing criteria ${ }^{9,10}$. For example, introducing heterologous pathways into model microorganisms and engineering them to maximize a particular biosynthesis has led to large scale production of 1,3-propanediol, farnesene, and artemisinin with many more on their way to market ${ }^{6,11}$. Efforts to make these molecules have resulted in success, but not without a great deal of challenges.

Bringing a biosynthetic molecule to market usually involves countless hours of design-build-test (DBT) cycles $^{12}$. The production of $n$-butanol is a prime example of these challenges. A series of Clostridia species are natural producers of $n$-butanol during acetone-butanol-ethanol fermentation, and Clostridia acetobutylicum and Clostridia beijerinckii are two of which are commonly used in commercial $n$-butanol plants $^{13}$. However, these species are difficult to engineer because of a biphasic metabolism, unknown regulation patterns, and a limited number of species-specific engineering tools ${ }^{14}$. Heterologous expression of Clostridia metabolism in model microorganisms like Escherichia coli and Saccharomyces cerevisiae allows $n$-butanol production to be more easily engineered but can be accompanied by lower titers ${ }^{15,16}$. 
Starting with heterologous expression of the $n$-butanol pathway as a baseline, scientists have been able to increase titers dramatically by knocking out genes from genomes ${ }^{15}$, increasing redox driving forces by introducing pathway-independent enzymes ${ }^{17}$, and identifying homologous enzymes with better activities ${ }^{18}$. Years of iterative metabolic engineering led to these advances, but titers are still not high enough and scale-up is often too unpredictable to outcompete natural producers for commercial production ${ }^{19}$. As is the same for many biosynthetic pathways, we cannot quickly enough identify optimal biosynthetic systems and discover the best sets of enzymes that work together as a group. Therefore, metabolic engineering remains costly and time-consuming ${ }^{20,21}$.

A key challenge in metabolic engineering is balancing the tug-of-war that exists between the cell's physiological and evolutionary objectives on one side and the engineer's process objectives on the other. Put another way, it is very difficult to balance intracellular fluxes to optimally satisfy a very active synthetic pathway while the machinery of the cell is functioning to maintain reproductive viability. Other challenges include: (i) the need for reliable computational selection and design of enzyme homologs for pathway design, (ii) the limited number of feasible homologs and genetic constructs that can be searched in any one project, and (iii) the unknown effects of optimal pathway enzyme expression on the entire metabolic system ${ }^{22-24}$.

Many established and emerging technologies seek to address these challenges. For example, metabolic flux analysis and genome engineering offer generalized capabilities to modify living organisms for improving product titers ${ }^{25,26}$. In addition, coupling machine-learning algorithms to multiplexed designs can accelerate efforts to rationally engineer cells ${ }^{27}$. However, DBT cycle time remains a limitation ${ }^{28}$. In vitro 
systems offer a complementary, yet underutilized approach to speed up DBT cycles with some potential advantages ${ }^{11,29-31}$. For example, the open reaction environment allows for the addition of components such as cofactors and intermediates at any time during a cell-free reaction, which can be maintained at precise concentrations. In addition, cell-free systems have no cell viability constraints. Furthermore, the cell-free format permits DBT iterations without the need to reengineer organisms ${ }^{30}$, with the potential to reduce DBT cycle time ${ }^{31}$. Cell-free metabolic engineering (CFME), or using cell-free techniques to aid metabolic engineering efforts, is emerging as a complementary approach to existing strategies for carrying out biomolecular transformations of interest with in vitro ensembles of catalytic proteins, prepared from purified enzymes or crude lysates of cells ${ }^{32-39}$.

In this work, we develop a cell-free protein synthesis driven metabolic engineering (CFPS-ME) framework to accelerate DBT cycles for optimizing and debugging biosynthetic pathways (Figure 1A). The foundational principle is that we can construct discrete metabolic pathways through combinatorial and modular assembly of lysates containing enzyme components produced by overexpression in the lysate chassis strain or by cell-free protein synthesis (CFPS). We focus on using CFPS because these systems can help address the growing demand for simple, inexpensive, and efficient protein production technologies for a wide array of applications ${ }^{11,29,40-44}$. In addition, processes that take days or weeks to design, prepare, and execute in cells can be done more rapidly in a cell-free system, because no time-consuming cloning steps are needed ${ }^{45}$. Three recent advances enable the use of CFPS for CFME. First, Jewett et al. demonstrated the ability to stimulate highly active energy and cofactor 
regeneration pathways in crude cell lysates ${ }^{46}$. Second, Kay and Jewett showed that crude cell lysate based cell-free systems from E. coli could fuel highly active heterologous metabolic transformations ${ }^{36}$. Third, Dudley and Jewett established the ability to build a heterologous biosynthetic pathway by mixing lysates each containing individually overexpressed heterologous enzymes (in preparation). The mix-and-match approach has many advantages including only needing to express one enzyme in each strain, not needing to fine-tune expression, and being able to directly monitor and sample the reaction environment. Here, we extend this approach by demonstrating modular assembly of pathways through the ability to enrich lysates with biosynthetic enzymes using well-defined experimental conditions and CFPS. It is important to note that our goal in this work was not to develop cell-free systems for the highest product titer, an engineered strain for best in vivo synthesis of $n$-butanol, or industrial applicability. However, we do show that CFPS-ME offers an even faster approach (hours rather than days) for building pathways directly in lysates for the purpose of enzyme selection and pathway design. 

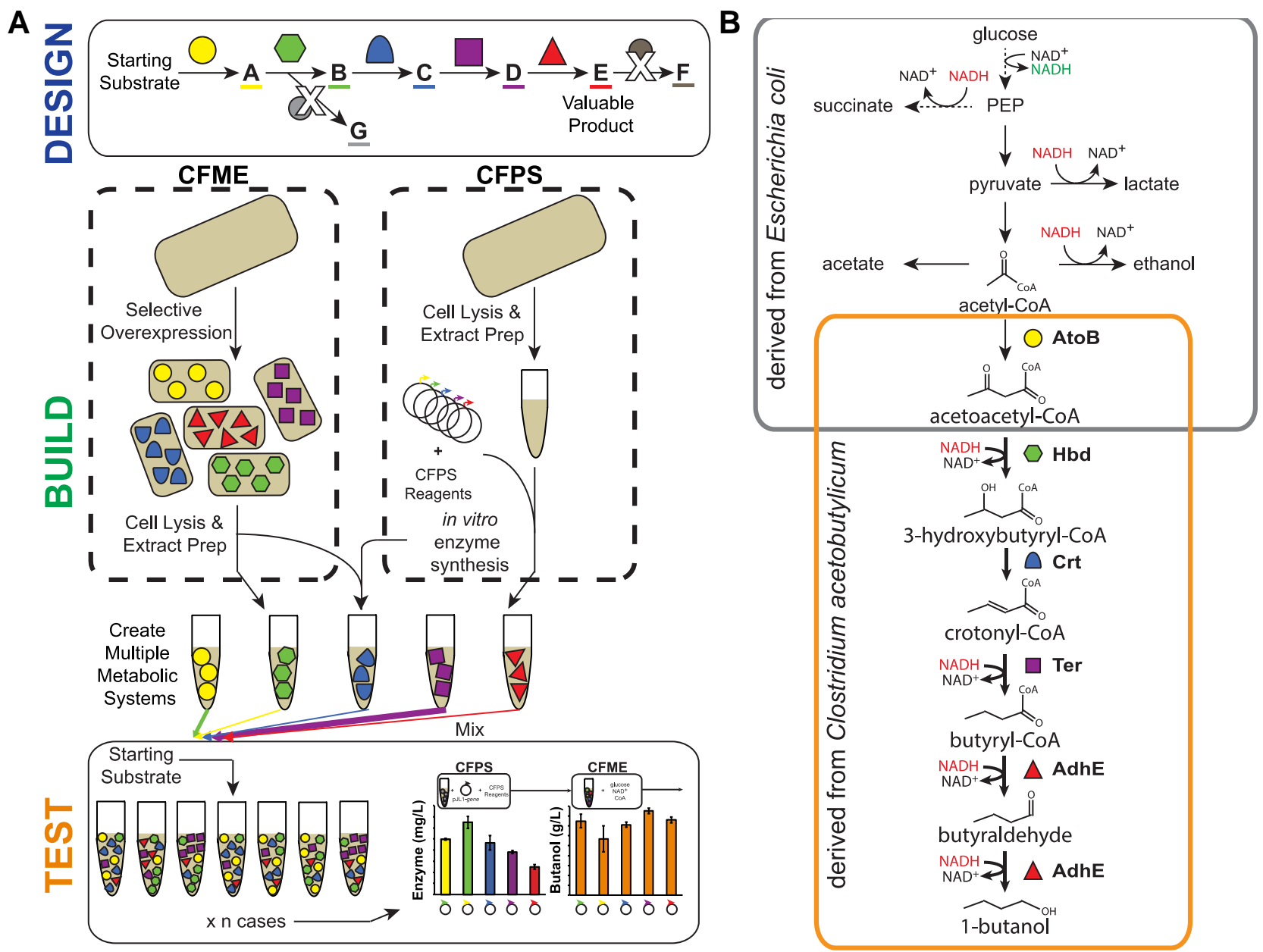

Figure 1. A cell-free framework for pathway prototyping demonstrated with a 17step $n$-butanol model pathway. (A) Methodology for cell-free metabolic engineering (CFME) and cell-free protein synthesis driven metabolic engineering (CFPS-ME). (B) Schematic (non-stoichiometric) representation of the constructed biosynthetic $n$-butanol pathway. Acetyl-CoA is generated through E. colis natural glycolysis and funneled into the $C$. acetobutylicum-derived CoA-dependent pathway to produce $n$-butanol. The butyryl-CoA dehydrogenase (Ter) here is from Treponema denticola. Four NADH molecules are needed to produce one molecule of $n$-butanol.

To demonstrate CFPS-ME, we selected the model $n$-butanol biosynthetic pathway derived from Clostridia metabolism involving CoA intermediates (Figure 1B). Endogenous glycolytic enzymes convert glucose to acetyl-CoA, the starting intermediate for $n$-butanol synthesis, another $E$. coli enzyme takes acetyl-CoA to acetoacetyl-CoA, and heterologous enzymes convert acetoacetyl-CoA to $n$-butanol. We 
first show the ability to mix five crude lysates each with selectively overexpressed enzymes to activate the entire 17-step $n$-butanol production pathway in vitro with high yield and productivities. We then establish the CFPS-ME concept by modularly building the $n$-butanol pathway with lysates harboring heterologous pathway enzymes expressed by CFPS or having been overexpressed in the chassis source strain. We apply this framework to rapidly screen enzymes for optimal pathway operation and enzyme discovery. We expect that the CFPS-ME framework will increase the resolution at which we can manipulate biosynthetic pathways by examining enzyme kinetics, measuring metabolic flux, determining catalyst stability, studying redox effects, and prototyping metabolism.

\section{Material and Methods}

\subsection{Bacterial strains and plasmids}

E. coli NEB Turbo ${ }^{\mathrm{TM}}$ (NEB) was used in plasmid cloning transformations and for plasmid preparation. E. coli BL21(DE3) (NEB) was used for protein overexpression and for preparation of all extracts (see Supplementary Table 1 for strain details). A modified version of $\mathrm{pET}$-22b (Novagen/EMD Millipore), used in previous studies ${ }^{36}$, was used for all constructs for in vivo over-expression of proteins. For in vitro expression of proteins, the pJL1 vector was used. Carbenicillin $\left(100 \mu \mathrm{gl}^{-1}\right)$ was used with the $\mathrm{pET}$ vector system and kanamycin $\left(50 \mu \mathrm{g} \mathrm{ml}^{-1}\right)$ was used with the $\mathrm{pJL} 1$ vector system.

Gibson assembly was used for seamless construction of plasmids (see Supplementary Table 1 for plasmid details). Each gene and vector was amplified via PCR using forward 
and reverse primers designed with NEB's Gibson Assembly Designer (New England Biolabs, Ipswich MA, USA) and purchased from IDT and Phusion ${ }^{\circledR}$ High-Fidelity DNA polymerase (Finnzymes, Thermo Scientific Molecular Biology) (see Supplementary Table 2 for genes and enzymes and Supplementary Table 3 for primer details). Both PCR products were cleaned and mixed with Gibson assembly reactants and incubated at $50^{\circ} \mathrm{C}$ for $60 \mathrm{~min}$. Plasmid DNA from the Gibson assembly reactions were immediately transformed into E. coli NEB Turbo cells. Propagated constructs were purified using an EZNA Plasmid Mini Kit (Omega Bio-Tek). Completed constructs were used to transform E. coli BL21(DE3).

Codon optimized versions of each gene were identified using IDT's codon optimization online tool (Integrated DNA Technologies ${ }^{\circledR}$, Coralville, USA) and NCBl's Basic Local Alignment Search Tool (National Center for Biotechnology Information, U.S. National Library of Medicine, Bethesda MD, USA). These genes were purchased from Gen9, Inc. (Cambridge MA, USA) (see Supplementary Table 4 for codon-optimized sequences).

\subsection{Cell Extract Preparation}

E. coli BL21(DE3) cells (see Supplementary Table 1 for strains) were grown in $2 \times$ YTPG media (16 $\mathrm{g} \mathrm{l}^{-1}$ tryptone, $10 \mathrm{~g} \mathrm{l}^{-1}$ yeast extract, $5 \mathrm{~g} \mathrm{l}^{-1} \mathrm{NaCl}, 7 \mathrm{~g} \mathrm{l}^{-1}$ potassium phosphate monobasic, $3 \mathrm{~g} \mathrm{I}^{-1}$ potassium phosphate dibasic, $18 \mathrm{~g} \mathrm{I}^{-1}$ glucose). These cells were cultured at the $50 \mathrm{ml}$ scale in $250 \mathrm{ml}$ baffled tunair shake flasks (IBI Scientific, Peosta, IA) in a $37^{\circ} \mathrm{C}$ incubator with vigorous shaking at $250 \mathrm{rpm}$. The cultured cells were monitored by spectrophotometry (Genesys 10S UV-Vis, Thermo Fisher Scientific, 
Waltham, MA). When cells reached $\mathrm{OD}_{600}=0.6-0.8$, the cultures were induced with 0.1 mM IPTG. After induction cultures were grown for $4 \mathrm{~h}$ at $30^{\circ} \mathrm{C}$. Antibiotics were not used during cell growth. The cells were harvested by centrifuging at $8,000 \mathrm{~g}$ at $4{ }^{\circ} \mathrm{C}$ for 15 min and were washed two times with cold S30 buffer (10 mM Tris-acetate (pH 8.2), $14 \mathrm{mM}$ magnesium acetate, and $60 \mathrm{mM}$ potassium glutamate). After final wash and centrifugation, the pelleted wet cells were weighed, flash frozen in liquid nitrogen, and stored at $-80^{\circ} \mathrm{C}$. The thawed cells were suspended in $0.8 \mathrm{ml}$ of $\mathrm{S} 30$ buffer per $1 \mathrm{~g}$ of wet cell mass. In order to lyse cells by sonication, thawed and suspended cells were transferred into $1.5 \mathrm{ml}$ microtube and placed in an ice-water bath to minimize heat damage during sonication. The cells were lysed using a Q125 Sonicator (Qsonica, Newtown, CT) with $3.175 \mathrm{~mm}$ diameter probe at frequency of $20 \mathrm{kHz}$ and $50 \%$ of amplitude. The input energy (Joules) was monitored and $830 \mathrm{~J}$ was used for $1.4 \mathrm{ml}$ of suspended cells. The lysate was then centrifuged twice at $21,100 \mathrm{~g}$ at $4{ }^{\circ} \mathrm{C}$ for $15 \mathrm{~min}$. All of prepared cell extract was flash frozen in liquid nitrogen and stored at $-80{ }^{\circ} \mathrm{C}$ until use.

\subsection{Extract Protein Quantification}

The total protein concentration of the extracts was measured by Quick-Start Bradford protein assay kits (Bio-Rad) with a bovine serum albumin standard. The extracts were subsequently run on a Coomassie-blue stained NuPAGE Bis-Tris 12\% SDS-PAGE gel with MOPS buffer (Life Technology, Grand Island, NY). The SeeBlue Plus2 pre-stained ladder (Life Technology, Grand Island, NY) was used and $\sim 10 \mu \mathrm{g}$ of total protein for each sample was loaded on the gel. 


\subsection{CFME Reactions}

Reactions were carried out in $1.5 \mathrm{ml}$ Eppendorf tubes at $37^{\circ} \mathrm{C}$ in $25 \mu \mathrm{l}$ volumes. Each reaction consisted of mixing five extracts, containing one enzyme overexpressed each, to complete the biosynthetic $n$-butanol pathway $\left(2 \mathrm{mg} \mathrm{ml}^{-1}\right)$ along with magnesium glutamate $(8 \mathrm{mM})$, ammonium glutamate $(10 \mathrm{mM})$, potassium glutamate $(134 \mathrm{mM})$, glucose (200 mM), dipotassium phosphate (10 mM, pH 7.2), Bis Tris (100 mM), NAD (1 $\mathrm{mM})$, ATP $(1 \mathrm{mM})$, and CoA $(0.5 \mathrm{mM})$, unless otherwise noted. Reactions were terminated by adding $5 \% \mathrm{w} / \mathrm{v}$ trichloroacetic acid in a $1: 1$ ratio. Precipitated proteins were pelleted by centrifugation at $15,000 \mathrm{~g}$ for $10 \mathrm{~min}$. The supernatant was stored at $-80{ }^{\circ} \mathrm{C}$ until analysis.

\subsection{CFPS-ME Reactions}

CFPS reactions were performed to express enzymes involved in $n$-butanol production prior to starting the CFME portion of the reactions using a modified PANOx-SP system $^{47}$. A $25 \mu$ l CFPS reaction in a $1.5 \mathrm{ml}$ microcentrifuge tube was prepared by mixing the following components: ATP (1.2 mM); GTP, UTP, and CTP (0.85 mM each); folinic acid $\left(34.0 \mathrm{\mu g} \mathrm{ml}^{-1}\right)$; E. coli tRNA mixture $\left(170.0 \mu \mathrm{g} \mathrm{ml}^{-1}\right)$; T7 RNA polymerase (100 $\left.\mathrm{g} \mathrm{m} \mathrm{m}^{-1}\right) ; 20$ standard amino acids (2 $\mathrm{mM}$ each); nicotinamide adenine dinucleotide (NAD; $0.33 \mathrm{~mm})$; coenzyme-A $(0.27 \mathrm{mM})$; spermidine $(1.5 \mathrm{mM})$; putrescine $(1 \mathrm{mM})$; potassium glutamate $(130 \mathrm{mM})$; ammonium glutamate $(10 \mathrm{mM})$; magnesium glutamate (12 mM); phosphoenolpyruvate (PEP; $33 \mathrm{mM})$, and cell extract $\left(10 \mathrm{mg} \mathrm{ml}^{-1}\right)$. For each reaction plasmid was added at $\sim 13.3$ or $\sim 26.6 \mathrm{\mu g} \mathrm{ml}^{-1}$. The $n$-butanol production portion 
of the reaction was initiated by spiking in glucose $(200 \mathrm{mM})$ and additional reagents (NAD, CoA) noted throughout the manuscript.

\subsection{Quantification of protein produced in vitro}

Cell-free protein synthesis reactions were performed as noted above (Section 2.5) with radioactive ${ }^{14} \mathrm{C}$-Leucine $(10 \mu \mathrm{M})$ supplemented in addition to all 20 standard amino acids. We used trichloroacetic acid (TCA) to precipitate radioactive protein samples. Radioactivity of TCA-precipitated samples was measured by liquid scintillation counting to then quantify the protein produced as previously reported (MicroBeta2; PerkinElmer $)^{46,47}$. These reactions were also run on a Coomassie-stained SDS-PAGE gel and exposed by autoradiography. Autoradiographs were imaged with a Typhoon 7000 (GE Healthcare Life Sciences, Pittsburgh, PA). Multiple proteins produced in vitro were further quantified by gel image intensity comparisons using Image $(\mathrm{NIH})$.

\section{7 n-Butanol Quantification}

High-performance liquid chromatography (HPLC) was used to analyze the components in the reactions. $n$-Butanol was measured with an Agilent 1260 series HPLC system (Agilent, Santa Clara, CA) via a refractive index (RI) detector. Analytes were separated using the Aminex HPX-87H anion exchange column (Bio-Rad Laboratories) with a $5 \mathrm{mM}$ sulfuric acid mobile phase at $55^{\circ} \mathrm{C}$ and a flow rate of $0.6 \mathrm{ml} \mathrm{min}^{-1}$. Commercial standard of $n$-butanol was used for quantification of experimental samples by linear interpolation of external standard curves. An example chromatogram for $n$-butanol is given in

\section{Supplementary Fig. 1.}




\section{Results}

In developing a framework for biosynthetic pathway prototyping, we constructed a 17-step pathway for the production of $n$-butanol. $n$-butanol synthesis was selected as a model because of its importance as a potential biofuel, it is easily quantified by HPLC, and it has multiple heterologous steps. We sought to combine E. coli's endogenous 11step glycolytic pathway from glucose to acetyl-CoA (AcCoA) with the Clostridia-derived six-step $n$-butanol pathway from AcCoA (Figure 1B). The idea that natural energy and cofactor regeneration would be harnessed in the lysate to fuel $n$-butanol production is a distinct break from typical in vitro approaches, which use purified enzymes ${ }^{32}$. Complementary to those systems, our approach allows for studying pathway performance in a setting that better mimics the in vivo operation (e.g., from glucose rather than $\mathrm{AcCoA}$ ). The crude lysate system also allows us to focus on expressing only the necessary heterologous enzymes to complete the entire pathway. These enzymes include a thiolase to merge two AcCoAs followed by a number of dehydrogenases to perform a series of reductions through CoA intermediates to obtain n-butanol (See Supplementary Table 2 for Genes and Enzymes).

\subsection{Cell-Free Metabolic Engineering for n-butanol Production}

To enable cell-free biosynthesis of $n$-butanol, we first introduced genes encoding the five enzymes needed to convert AcCoA to $n$-butanol individually into our extract source strains, in this case BL21(DE3) (See Supplementary Table 1 for Strains and Plasmids and Supplementary Table 3 for Primers). We selected two homologs each for hydroxybutyryl-CoA dehydrogenase $(\mathrm{Hbd})$, crotonase $(\mathrm{Crt})$, and bifunctional 
aldehyde/alcohol dehydrogenase functionalities. For the thiolase (AtoB) and butyrylCoA dehydrogenase (Ter) we chose E. colis endogenous enzyme and a widely used enzyme from Treponema denticola, respectively. Next, we selectively overexpressed each heterologous enzyme in separate strains using a tightly controlled T7 promoter and strong ribosome binding site. As expected, we observed that the heterologous proteins were overexpressed as the dominant bands, with the exception of $\mathrm{Hbd} 1$, on an SDS-PAGE gel (Figure 2A). The low expression of Hbd1 is likely due to RBS used for expression.
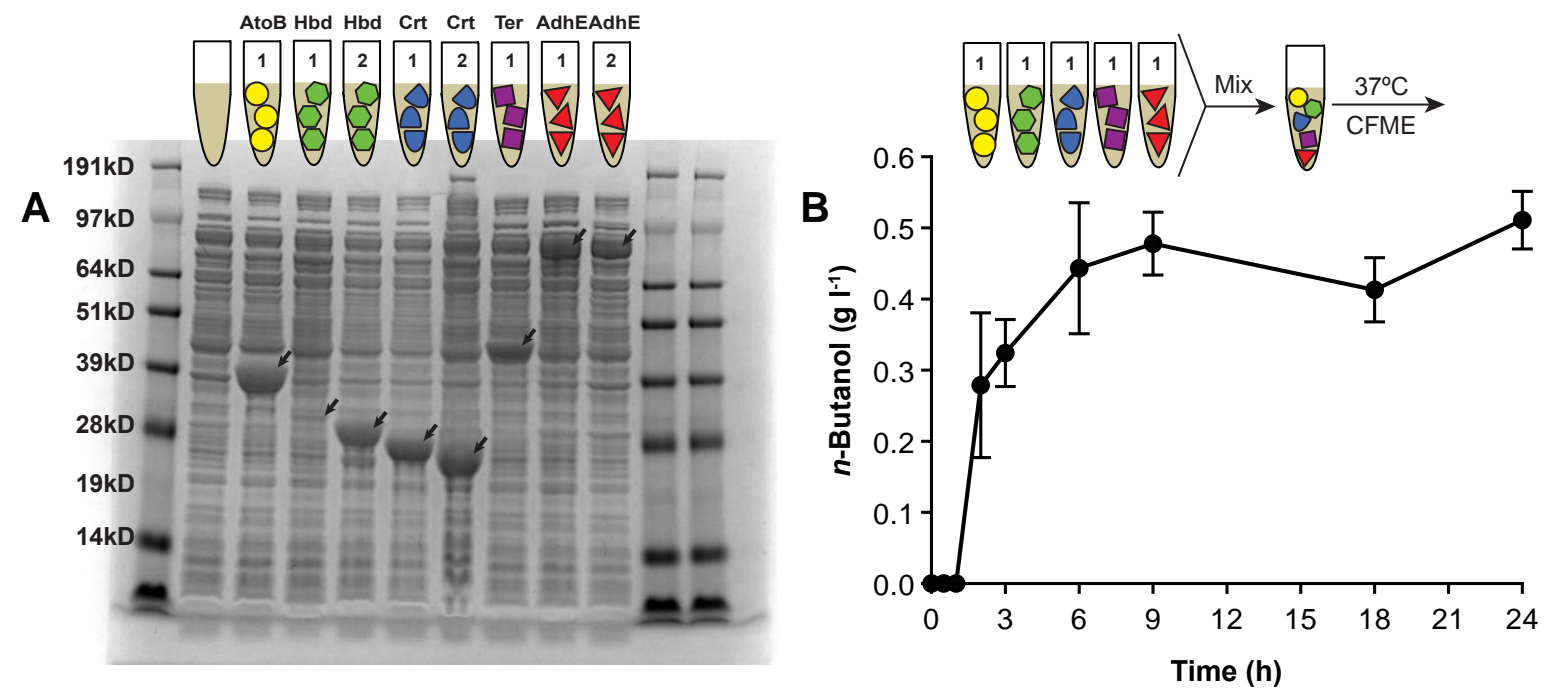

Figure 2. Biosynthesis of $n$-butanol achieved via CFME of a coupled $E$. coli and $C$. acetobutylicum metabolic pathway. (A) Via SDS-PAGE, the gel verifies the selective overexpression of pathway enzymes in E. coli BL21(DE3) crude cell lysates: AtoB (Escherichia coli), Hbd1 (Clostridia acetobutylicum, CA), Hbd2 (Clostridia beijerinckii, $C B$ ), Crt1 (Clostridium acetobutylicum, CA), Crt2 (Pseudomonas putida, PP), Ter (Treponema denticola, TD), AdhE1 (Clostridium acetobutylicum, CA), and AdhE2 (Clostridium pasteurianum, CP). (B) CFME reactions for $n$-butanol production from glucose were carried out using five crude lysates mixed together (1:1:1:1:1 based on total protein quantification) with glutamate salts $\left(\mathrm{Mg}^{+}, \mathrm{NH}_{4}{ }^{+}, \mathrm{K}^{+}\right)$, phosphate $\left(\mathrm{K}_{2} \mathrm{HPO}_{4}\right)$, buffer (Bis Tris), and cofactors (ATP, CoA, NAD ${ }^{+}$. These lysates individually contained AtoB (EC), Hbd1 (CA), Crt1 (CA), Ter1 (TD), and AdhE1 (CA) selectively overexpressed at $37^{\circ} \mathrm{C}$. Error bars represent standard deviations with $\mathrm{n} \geq 3$ independent reactions. 
After lysis and extract preparation, we then reconstituted the 17-step pathway from glucose to $n$-butanol by mixing equal total protein concentrations of five separate extracts containing each enzyme. Specifically, we started with the following enzyme set: E. coli's AtoB, C. acetobutylicum's $\mathrm{Hbd}$, Crt, and AdhE2, as well as Ter from $T$. denticola. This set was chosen to include most of $C$. acetobutylicum's enzyme set, one of the most widely used sets for $n$-butanol production, along with previously identified best enzymes for thiolase and butyryl-CoA dehydrogenase functions ${ }^{17,19}$. Upon incubation with essential substrates, salts, and cofactors (e.g., magnesium, potassium, and ammonium salts, glucose, phosphate, buffer, NAD, CoA, ATP), we assessed $n$ butanol synthesis in $25 \mu$ l CFME batch reactions carried out for $24 \mathrm{~h}$ at $37{ }^{\circ} \mathrm{C}$ via high performance liquid chromatography (HPLC). We observed production of $0.51 \pm 0.04 \mathrm{~g} \mathrm{l}^{-}$ ${ }^{1} n$-butanol ( $0.05 \mathrm{~mol} n$-butanol / mol glucose) over the course of a $24 \mathrm{~h}$ reaction (Figure 2B), without any optimization to improve titers. As expected, we also observed lactate, acetate, and ethanol as byproducts seen in previous reports of $n$-butanol production, which could be addressed through genome modifications (e.g., deletion of Idh gene in the source strain $)^{19}$. Butanol production shows that both the heterologous pathway and endogenous glycolysis is activated with cofactors being regenerated. However, $n$-butanol production stops after $\sim 9$ h. In previous work, substrate depletion was shown to be the most typical cause for reaction termination ${ }^{36}$. One way to avoid this limitation is to run reactions in fed-batch or continuous reactor set-ups or use substrates that are metabolized slower (e.g. polymeric sugars). Except in few instances ${ }^{39,48}$, limited cofactor regeneration has historically plagued in vitro synthetic enzymatic pathway conversions ${ }^{32,34,35}$. Here, however, native glycolytic enzymes in the lysate provide a 
simple route to fuel highly active heterologous metabolic conversions. For example, to produce $\sim 7 \mathrm{mM}$-butanol we would need $\sim 56 \mathrm{NADH}$ turnover events, exceeding typical turnover numbers of $\sim 5-20$ for purified in vitro systems ${ }^{32}$.

Following demonstration of activating $n$-butanol synthesis, we next aimed to modularly build $n$-butanol synthesis pathways with different enzyme homologs to improve pathway performance. We cycled through multiple distinct ensembles of enzymes by mixing and matching lysates containing different versions of enzymes necessary to complete the biosynthetic $n$-butanol pathway. Trying out different homologs in this manner allowed us to quickly identify a better set of enzymes producing $n$-butanol at $0.84 \pm 0.19 \mathrm{~g} \mathrm{l}^{-1}(0.09 \mathrm{~mol} n$-butanol / mol glucose) (Figure 3A). Specifically, we showed that $\mathrm{Hbd} 2$ from $C$. beijerinckii enabled a $65 \%$ increase in $n$ butanol synthesis titers over $\mathrm{Hbd} 1$ from $C$. acetobutylicum. A follow-up experiment doubling the Hbd1 enzyme did not alter the amount of $n$-butanol produced, suggesting that this increase was not due to discrepancies in enzyme concentrations in the lysate (Supplementary Fig. 2). However, further studies of these enzymes would elucidate whether the observed $n$-butanol production was a result of using BL21(DE3) extract without heterologous genes expressed (used for normalization), which may have more active glycolytic and byproduct pathways that could divert flux away from $n$-butanol. 

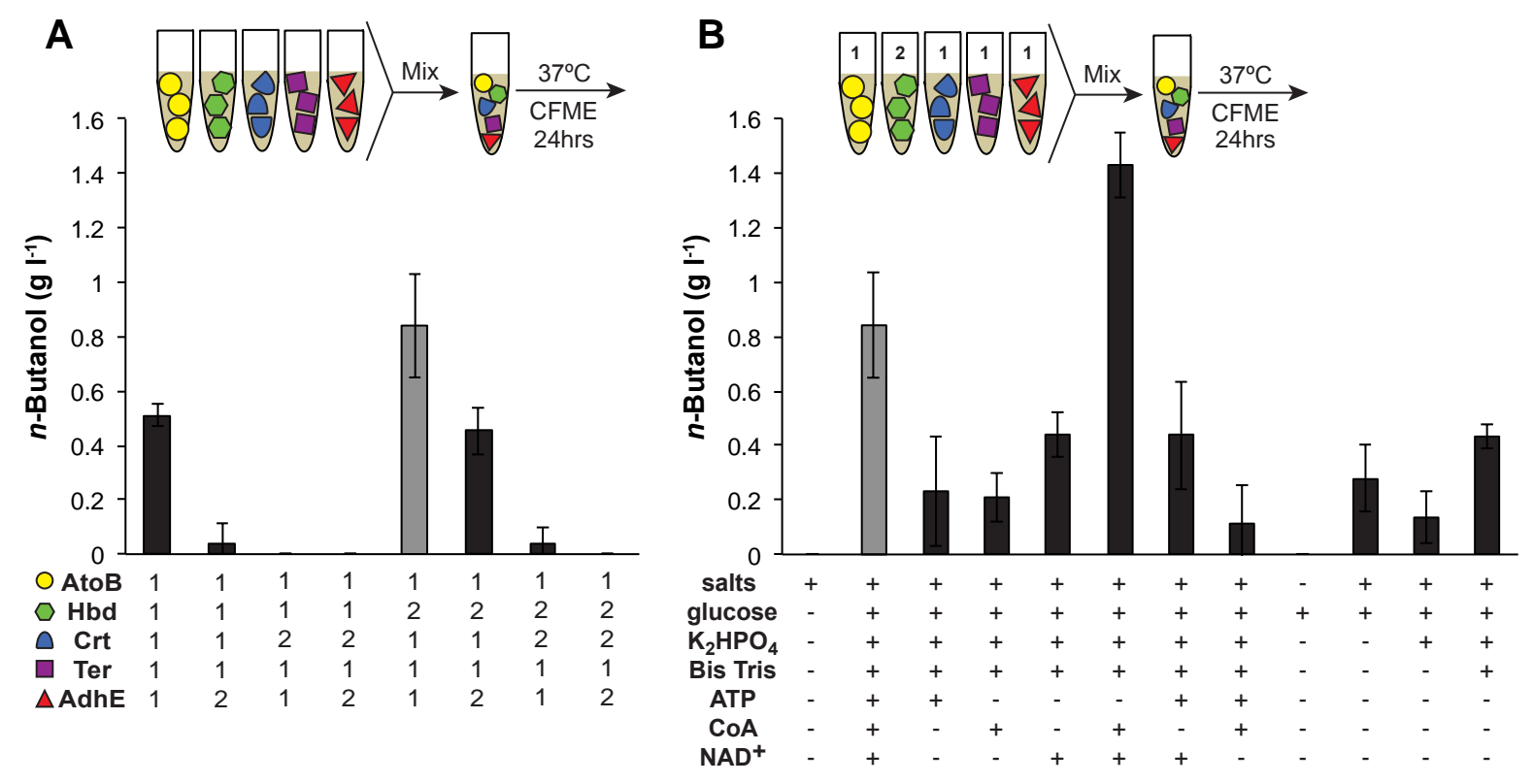

Figure 3. Enzyme and physiochemical optimizations lead to increased yields of CFME $n$-butanol production. (A) Reactions for $n$-butanol production from glucose were performed using different sets of five crude lysates mixed together to obtain unique combinations of selectively overexpressed enzymes with AtoB, Hbd, Crt, Ter, and AdhE activities. Lysate mixes were combined with glutamate salts $\left(\mathrm{Mg}^{+}, \mathrm{NH}_{4}{ }^{+}, \mathrm{K}^{+}\right)$, phosphate $\left(\mathrm{K}_{2} \mathrm{HPO}_{4}\right)$, buffer (Bis Tris), and cofactors (ATP, CoA, NAD ${ }^{+}$) and incubated for $24 \mathrm{~h}$ at $37^{\circ} \mathrm{O}$. (B) To enhance yields and optimize pathway performance, a physiochemical optimization was performed with or without glutamate salts $\left(\mathrm{Mg}^{+}, \mathrm{NH}_{4}{ }^{+}\right.$, $\mathrm{K}^{+}$), phosphate $\left(\mathrm{K}_{2} \mathrm{HPO}_{4}\right)$, buffer (Bis Tris), and cofactors (ATP, CoA, NAD $\left.{ }^{+}\right)$) of cell-free reactions producing $n$-butanol. Reactions incubated for $24 \mathrm{~h}$ at $37^{\circ} \mathrm{C}$. The grey bars represent the same recipe in (A) and in (B). All error bars represent standard deviations with $n \geq 3$ independent reactions.

While the selection of enzymes is crucial to improving $n$-butanol production, the value of each physiochemical parameter of the cell-free system also affects $n$-butanol production and becomes key in further optimization and debugging of the pathway. To demonstrate the facile nature of combinatorial optimizations in our cell-free framework, we explored changes in the ionic composition because the composition of salts added to in vitro systems affects the systems' performance ${ }^{46,47,49,50}$. Specifically, we tested the effect of using glutamate, acetate, and chloride salts on $n$-butanol production and found 
that glutamate salts perform more than $15 \%$ better than the other salt compositions (Supplementary Fig. 3). Our results are consistent with previous works, which have shown that glutamate salts better mimic the intracellular cytoplasmic conditions of $E$. coli to co-activate authentic biological processes such as the in vitro co-activation of central metabolism, oxidative phosphorylation, and protein synthesis ${ }^{46}$.

Beyond studying pathway performance by altering the ionic composition, the states of critical cofactors (organic molecules necessary for enzyme catalysis) can also be studied. The balance of cofactors, such as oxidized and reduced NAD, is critical to energy regeneration within the lysate by also the heterologous pathway under investigation. In our cell-free framework, the lack of a cell wall enables direct sample acquisition, reaction monitoring, and control. We used this flexibility to study the impact of the ratio of initial cofactors in the reaction to see the ratio's effect on $n$-butanol production. We found that the ratio of $N A D(H)$ at the start of the reaction (e.g., NAD:NADH: 1:0, 1:0.5, 1:1, 0.5:1, 0:1), keeping the total cofactor concentration at 0.5 $\mathrm{mM}$, plays a minimal role in how much $n$-butanol can be produced (Supplementary Fig. 4). This suggests that metabolism in the lysate may control the overall levels of reduced and oxidized cofactor, which is consistent with data from Kay and Jewett ${ }^{36}$.

Understanding that some components play more of a role in pathway performance than others, we next performed a number of reactions to identify which added components are necessary for $n$-butanol production with a particular interest in the three added cofactors (ATP, NAD, and CoA). The supplementation of cofactors to cell-free reactions would be costly and hinder industrial practicality of this technology if it were proposed as a biomanufacturing platform. In our study of cell-free systems as a 
prototyping framework, we surprisingly found that omitting ATP boosts $n$-butanol production by greater than $180 \%$ from $0.84 \pm 0.19 \mathrm{~g} \mathrm{l}^{-1}$ to $1.43 \pm 0.12 \mathrm{~g} \mathrm{l}^{-1}(0.11 \mathrm{~mol} n$ butanol / mol glucose) (Figure 3B). More unexpectedly, by just adding salts to mimic the cytoplasm and glucose as a starting substrate we are able to produce $n$-butanol at $0.28 \pm 0.12 \mathrm{~g} \mathrm{l}^{-1}$. In other words, if lysates are prepared without dialysis, as we have done, cofactors remaining in the lysate are sufficient for the cell-free transformation and do not need to be added. Collectively, our results here show that the cell-free framework offers a strategy to explore how enzyme variants, substrates, cofactors, ionic composition, etc. can be varied in unique combinations to influence pathway performance. While CFME (i.e., selective enriching or functionalizing the lysate with pathway enzymes prior to extract generation) provides us with a rather quick way to screen enzyme ensembles and reaction conditions, this approach is limited by the cell's ability to produce the enzymes individually in vivo, a limitation that we address below.

\subsection{Cell-Free Protein Synthesis Driven Metabolic Engineering}

We next aimed to combine CFPS and CFME to modularly build the $n$-butanol pathway for forward engineering. This is dissimilar from previous works in which synthetic in vitro pathways have been built by purified enzymes or using lysates selectively enriched by heterologously expressed enzymes. Integration of CFPS enables one to speed up DBT cycle time for prospecting biosynthetic pathways. Indeed, using CFPS to express enzymes can reduce the time to build pathways to hours rather than days. As a proof-of-concept of this approach, we tested making $\mathrm{Hbd} 2$ (the nonnative entry enzyme to the pathway) by CFPS to activate $n$-butanol production (Figure 
4A). The key idea of the experiment was that the pathway would remain inactive (as downstream enzymes will not have their substrates) until active Hbd2 was synthesized. We chose to validate CFPS-ME in a three-step process. First, we quantified our ability to express $\mathrm{Hbd} 2$ in a CFPS reaction comprised of a mixture of lysates harboring selectively enriched pathway enzymes lacking $\mathrm{Hbd} 2$. This was important because typical CFPS systems use lysates from cells harvested in mid-late exponential phase, where as our lysates were collected $4 \mathrm{~h}$ post-induction of pathway enzymes. Second, we studied the ability to activate the entire pathway by combining CFPS and CFME. Third, we carried out a series of optimizations to try to increase yields.

A

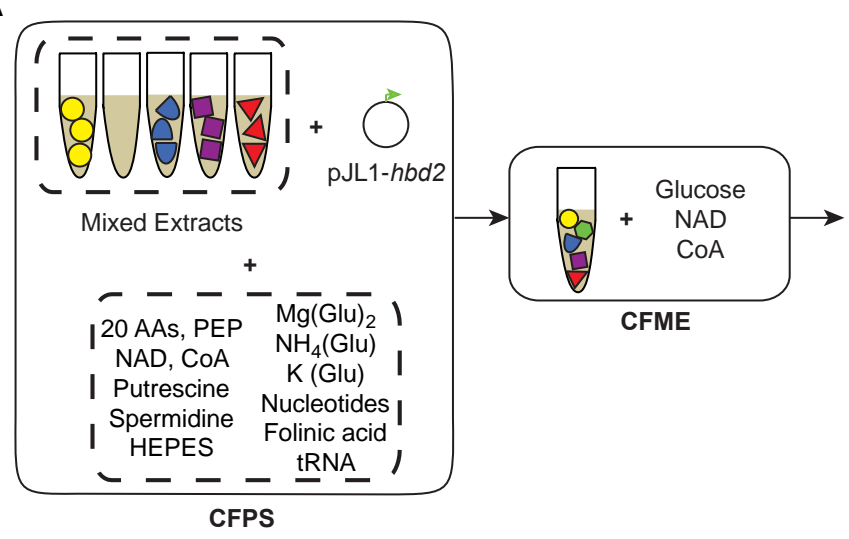

C

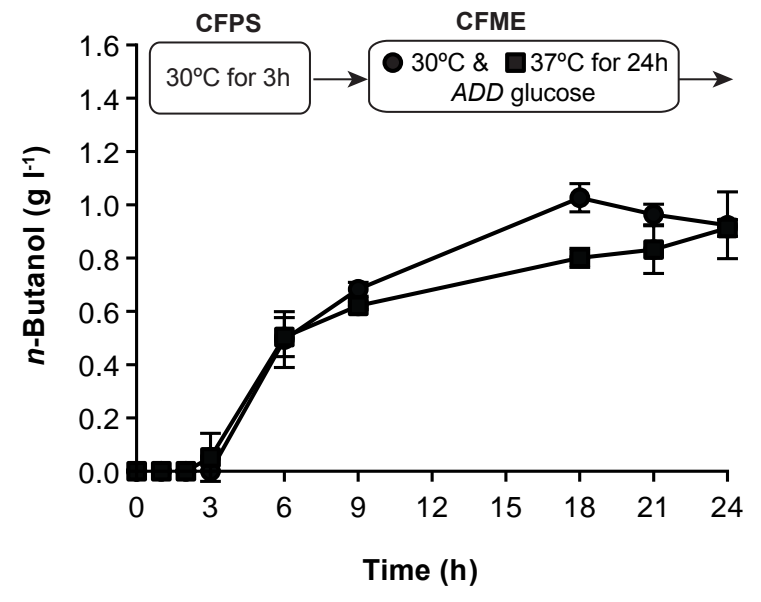

B
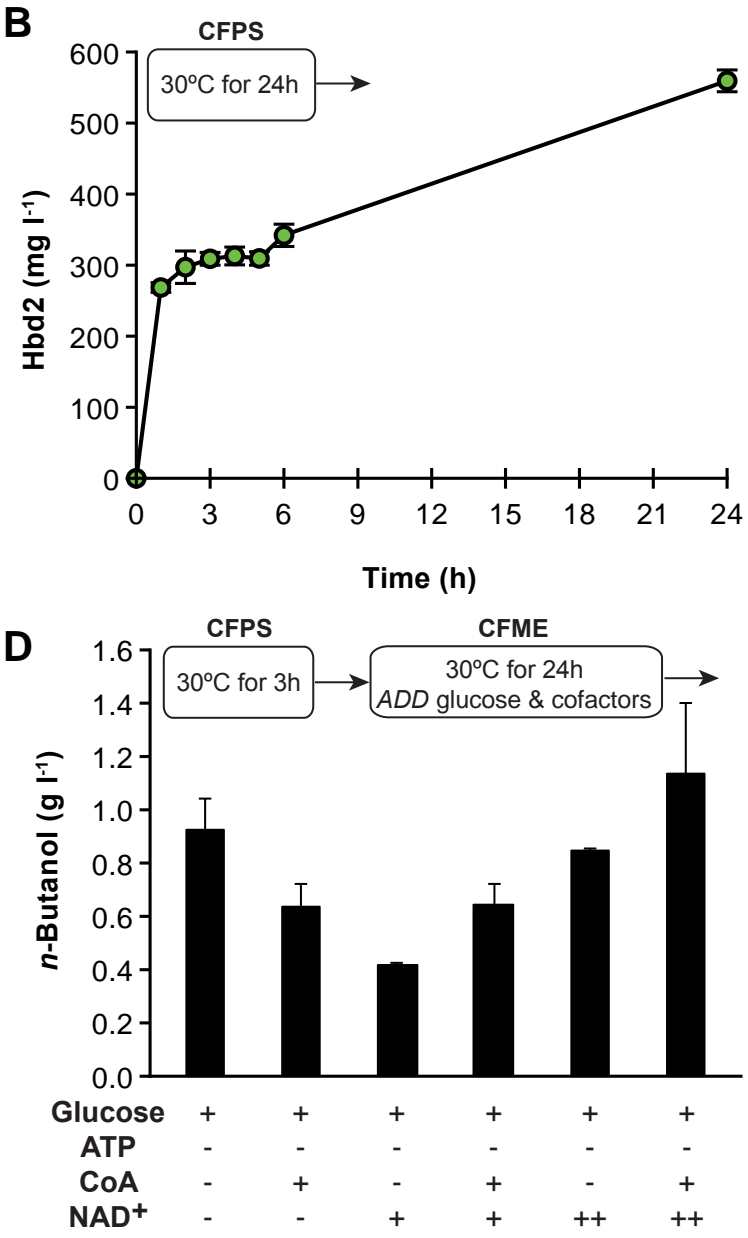

Figure 4. Cell-free protein synthesis of entry enzyme activates $n$-butanol production in vitro by CFPS-ME approach. (A) Diagram describing the CFPS-ME 
experimental design. (B) Cell-free protein synthesis titers of Hbd2 from pJL1-hbd2 in a crude lysate mixture containing AtoB (EC), Crt1 (CA), Ter1 (TD), and AdhE1 (CA) overexpressed as determined by radioactive ${ }^{14} \mathrm{C}$-leucine incorporation. CFPS reactions incubated over a 24 -hr period at $30^{\circ} \mathrm{C}$. (C) $n$-butanol production in the same mixed lysate system activated by cell-free protein synthesis of $\mathrm{Hbd} 2$ run at $30{ }^{\circ} \mathrm{C}$ for $3 \mathrm{~h}$. Glucose was added to activate the $n$-butanol pathway and CFME reactions were incubated over a $24-\mathrm{hr}$ period at both $30^{\circ} \mathrm{C}$ and $37^{\circ} \mathrm{C}$. (D) Cofactor (ATP, CoA, NAD ${ }^{+}$) optimization of downstream (ME portion of the CFPS-ME approach) cell-free reactions producing $n$-butanol were performed. Minus (-) signs represent no cofactor added, plus (+) signs represent $\mathrm{mM}$ amounts of cofactor to match conditions in CFME-alone experiments, and plus-plus (++) reactions represent double the amount of that cofactor. Reactions incubated for $24 \mathrm{~h}$ at $30 \stackrel{\circ}{\circ}$. All error bars represent standard deviations with $n \geq 3$ independent reactions.

For CFPS, we used the tunable and well characterized PANOx-SP CFPS system developed by Jewett and Swartz ${ }^{47}$ to quantitatively test the synthesis of Hbd2. CFPS reactions at $30{ }^{\circ} \mathrm{C}$ were allowed to run for $24 \mathrm{~h}$ in batch operation and the yields of cellfree synthesized Hbd2 was quantified by monitoring ${ }^{14} \mathrm{C}$-leucine incorporation. We based the system on a mixture of lysates used above, except the lysate with $\mathrm{Hbd} 2$ was not included. Endogenous protein synthesis machinery should act to synthesize and fold desired protein products upon incubation with essential substrates (e.g., amino acids, nucleotides, DNA or mRNA, energy substrates, cofactors, and salts). In this case, we showed that when the DNA for the Hbd2 enzyme on a pJL1 vector was added, the mixed extract could produce $559 \pm 15 \mathrm{mg} \mathrm{l}^{-1}$ of Hbd2 over a 24-hour period (Figure 4B). Based on this result and the fact that this reaction was over $50 \%$ complete by three hours, we chose to run all subsequent CFPS reactions for three hours, which should provide sufficient protein quantities for prototyping.

We next investigated the ability of the cell-free synthesized $\mathrm{Hbd} 2$ to activate the full $n$-butanol pathway. After three hours of CFPS, we initiated $n$-butanol metabolism by adding $200 \mathrm{mM}$ glucose to the reactions. We showed that CFPS of Hbd2 could activate 
$n$-butanol metabolism reaching a titer of $0.92 \pm 0.13 \mathrm{~g} \mathrm{I}^{-1}$ (Figure 4C). Negative control reactions without synthesis of the $\mathrm{Hbd} 2$ did not produce $n$-butanol. Notably, the CFME portion resulted in the same $n$-butanol yields when carried out at either 30 or $37^{\circ} \mathrm{C}$, so for ease we selected $30 \stackrel{\circ}{\circ}$ for all future experiments to have the CFPS and CFME portions performed at the same temperature. As in the CFME system alone, we found that small molecules, cofactors, etc. can modulate pathway performance. For example, we found that adding both NAD and CoA with glucose to initiate $n$-butanol metabolism after CFPS gave us $1.22 \pm 0.22 \mathrm{~g} \mathrm{l}^{-1} n$-butanol (Figure 4D). Collectively, our results prove for the first time to our knowledge the ability to combine CFPS and CFME to support a highly active biosynthetic pathway.

We further extended this proof-of-concept to activate $n$-butanol production using CFPS at any pathway node by producing each $n$-butanol pathway enzyme. Using mixed extracts with all but one necessary enzyme, we performed CFPS of the 'missing enzyme' and saw that each enzyme could be produced individually at more than 100 $\mathrm{mg} \mathrm{l}^{-1}$ without optimization (Figure 5A). We then proved that full product of each protein is made exclusively in each reaction by an autoradiogram (Supplementary Fig. 5). After validating expression of each enzyme, we then performed CFPS-ME reactions. We carried out three-hour CFPS reactions and then initiated the $n$-butanol pathway by adding glucose, NAD, and CoA, because supplementation of CFPS-ME reactions with both NAD and CoA increased $n$-butanol titers for Hbd2 (Figure 4D). Strikingly, CFPSME could be used for each of the pathway enzymes to produce $n$-butanol at levels as high as $1.71 \pm 0.06 \mathrm{~g} \mathrm{l}^{-1}$ (Figure 5B). 


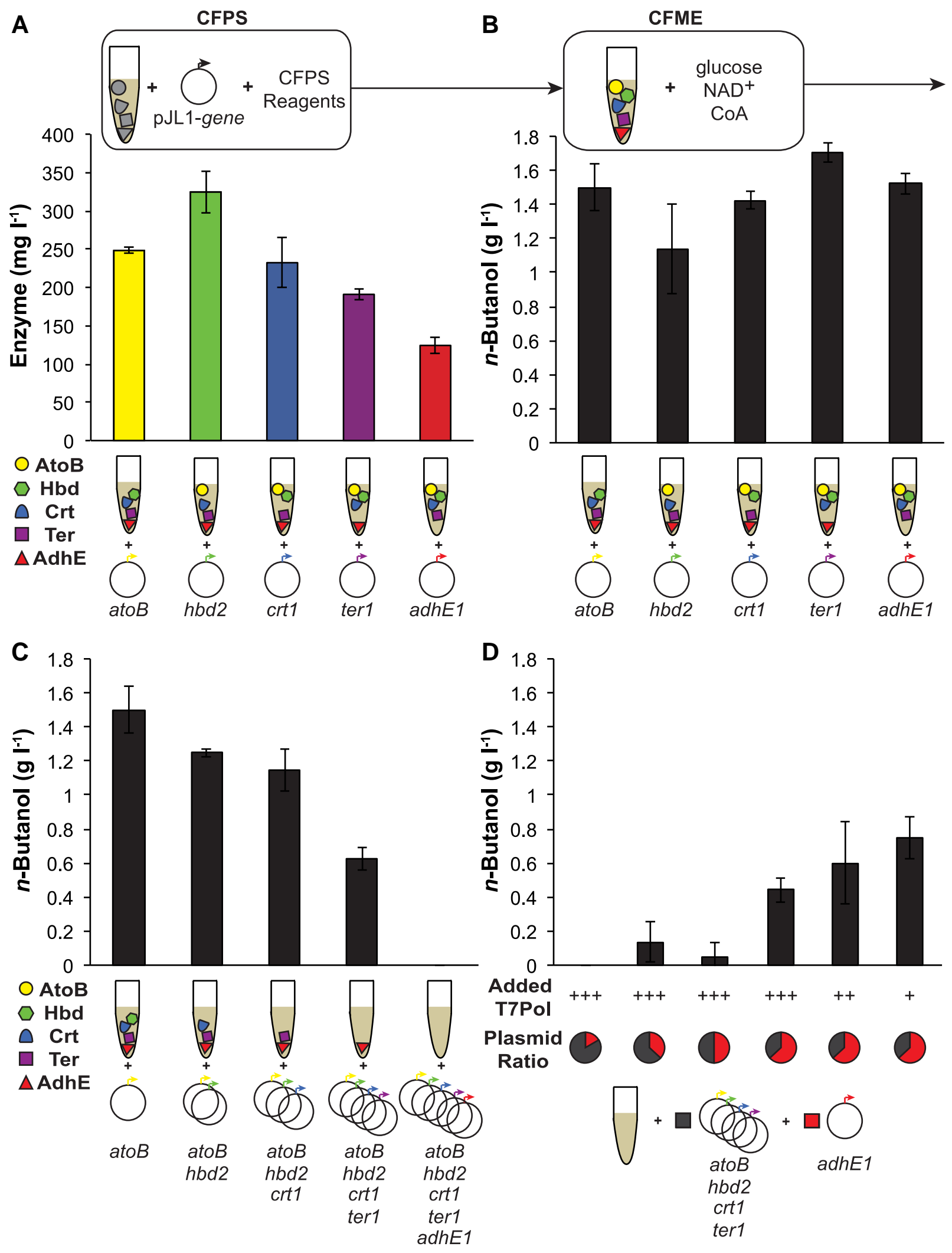

Figure 5. Using cell-free protein synthesis to activate metabolism from any node 
in the biosynthetic pathway. (a) Cell-free protein synthesis titers of AtoB (EC), Hbd2 (CB), Crt1 (CA), Ter1 (CA), and AdhE1 (CA) off pJL1 constructs in separate reaction mixtures as determined by radioactive ${ }^{14} \mathrm{C}$-leucine incorporation. Each reaction mixture contained crude lysates with all pathway enzymes except the one made by CFPS. CFPS reactions were incubated for $3 \mathrm{~h}$ at $30^{\circ} \mathrm{C}$. (b) $n$-butanol production in the same mixed lysate system activated by CFPS of each enzyme run at $30^{\circ} \mathrm{C}$ for $3 \mathrm{~h}$. Glucose, $\mathrm{CoA}$, and $\mathrm{NAD}^{+}$were added to activate the $n$-butanol pathway and CFME reactions were incubated for $24 \mathrm{~h}$ at $30^{\circ} \mathrm{C}$. (c) $n$-butanol production activated by CFPS of enzymes in combinations: (1) AtoB (EC); (2) AtoB (EC) and Hbd2 (CB); (3) AtoB (EC), $\mathrm{Hbd} 2$ (CB), and Crt1 (CA); (4) AtoB (EC), Hbd2 (CB), Crt1 (CA), and Ter1 (TD); and (5) AtoB (EC), Hbd2 (CB), Crt1 (CA), Ter1 (TD), and AdhE1 (CA). The CFPS reactions were run at $30^{\circ} \mathrm{C}$ for $3 \mathrm{hrs}$. Glucose, CoA, and $\mathrm{NAD}^{+}$were added to activate the $n$ butanol pathway and reactions were incubated for $24 \mathrm{~h}$ at $30{ }^{\circ} \mathrm{C}$. (d) A plasmid ratio optimization of pJL1-adhE1 vs. all other pJL1 constructs along with a test of three concentrations of T7 polymerase. For each, CFPS was run at $30^{\circ} \mathrm{C}$ for $3 \mathrm{~h}$. Glucose, $\mathrm{CoA}$, and $\mathrm{NAD}^{+}$were added to activate the $n$-butanol pathway and reactions were incubated for $24 \mathrm{~h}$ at $30^{\circ} \mathrm{C}$. All error bars represent standard deviations with $\mathrm{n} \geq 3$ independent reactions.

We next set out to demonstrate we could build the entire pathway by CFPS of the pathway enzymes in our extracts. To this end, we extended the number of enzymes made in vitro one by one, by adding equal amounts of DNA of each, and saw that when we made one, two, three, and four of the five enzymes necessary in vitro we could produce $n$-butanol at levels between $\sim 0.6$ and $\sim 1.4 \mathrm{~g} \mathrm{l}^{-1}$ (Figure 5C). Again, full-length product of each protein is made in each reaction as shown by autoradiogram (Supplementary Fig. 6). However, as we increase the number of enzymes produced by CFPS, the amount of $n$-butanol synthesized decreases. In fact, when we tried to produce all five enzymes in vitro we were initially unable to make any $n$-butanol. We attribute this drop in $n$-butanol production to there not being enough of the last enzyme in the pathway, AdhE, seen by quantification of the enzymes produced by CFPS (Supplementary Fig. 7). However, we were able to make all enzymes in vitro at sufficient levels necessary to make $n$-butanol at $0.75 \pm 0.12 \mathrm{~g} \mathrm{l}^{-1}$ by increasing the plasmid DNA encoding AdhE to more than $50 \%$ of the total DNA added, (Figure 5D; 
Supplementary Fig. 8). Reduced T7 polymerase added shows improvements in $n$ butanol production. Typical CFPS systems supplement T7 polymerase stored in glycerol, and increasing glycerol concentrations can be deleterious to the CFPS system. The extract used in this study contains T7 polymerase expressed in vivo prior to extract preparation, so $\mathrm{T} 7$ polymerase in the extract is expected to be sufficient without supplementation. Based on our result that added ATP was deleterious to $n$-butanol production by CFME (Figure 3B), the ATP used in CFPS might be expected to inhibit CFPS-ME $n$-butanol titers if ATP is long-lived. We have previously shown that ATP concentrations are stable around $200 \mu \mathrm{M}$ over a $\sim 6-8$ hour batch CFPS reaction ${ }^{47}$. Though, a negative effect from ATP is expected, it is difficult to use the CFME optimization conditions for CFPS-ME, given the added complexity of protein synthesis. Our results importantly showed that we could build a five-step heterologous pathway to make $n$-butanol in vitro in three hours.

\subsection{Rapid Prototyping and Enzyme Discovery with CFPS-ME}

The ability to use CFPS-ME to produce enzymes for $n$-butanol biosynthesis allows us to test pathway enzymes without expressing enzymes in the host cell. As a model case study, we decided to test for improved pathway performance (increased $n$ butanol production) by swapping out some of our initial Ter and AdhE enzymes for a variety of homologs. In less than a day, we studied 4 Ter and 3 AdhE homologs in a combined CFPS-ME reaction. In all cases, we observed synthesis of $n$-butanol, though lower than our previous best-performing enzymes (Figure 6A). Five of these variants come from species never tested before. 

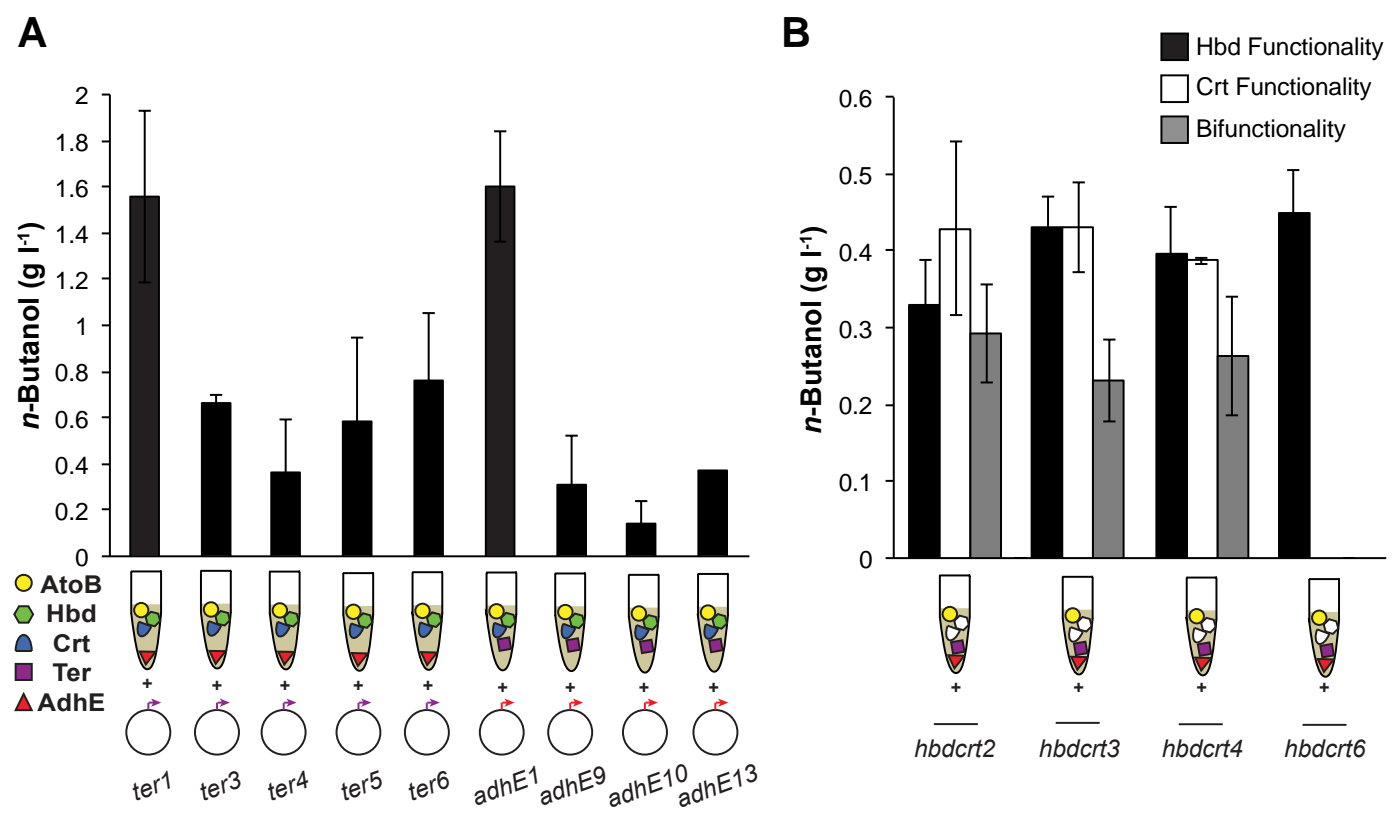

Figure 6. Using CFPS-ME to rapidly screen pathway enzymes. (A) n-butanol production activated by CFPS of unique Ter homologs and AdhE homologs from pJL1 constructs: Ter3 (Fibrobacter succinogenes, FS), Ter4 (Flavobacterium johnsoniae, FJ), Ter5 (Spirochaeta bajacaliforniensis, SB), Ter6 (Cytophaga hutchinsonii, CH), AdhE9 (Thermosynechococcus sp. NK55a, TN), AdhE10 (Providencia burhodogranariea, PB), and AdhE13 (Serratia marcescens, SM). Ter homologs were expressed in crude lysate mixtures containing AtoB (EC), Hbd2 (CB), Crt1 (CA), and AdhE1 (CA) overexpressed, and AdhE homologs were expressed in lysates containing AtoB (EC), Hbd2 (CB), Crt1 (CA), and Ter1 (TD) overexpressed. (B) $n$-Butanol production activated by CFPS putative bifunctional enzymes for Hbd and Crt activity: Hbdcrt2 (Aeropyrum camini, $A C$ ), Hbdcrt3 (Pyrobaculum aerophilum, PA), Hbdcrt4 (Sulfolobus islandicus, SI), and Hbdcrt6 (Sulfolobus acidocaldarius, SA). CFPS reactions were performed from linear DNA in crude lysate mixtures containing: (1) AtoB (EC), Ter1 (TD), and AdhE1 (CA) overexpressed to test bifunctionality, (2), AtoB (EC), Crt1 (CA), Ter1 (TD), and AdhE1 (CA) overexpressed to test $\mathrm{Hbd}$ functionality alone, and (3) AtoB (EC), Hbd2 (CB), Ter1 (TD), and AdhE1 (CA) overexpressed to test Crt functionality alone. For each, CFPS was run at $30 \stackrel{\circ}{ } \mathrm{C}$ for $3 \mathrm{~h}$. Glucose, $\mathrm{CoA}$, and $\mathrm{NAD}^{+}$were added to activate the $n$-butanol pathway and reactions were incubated for $24 \mathrm{~h}$ at $30^{\circ} \mathrm{C}$. All error bars represent standard deviations with $n \geq 3$ independent reactions.

Having demonstrated the ability to explore enzyme homologs using CFPS-ME, we then set out to demonstrate the potential for using linear DNA templates instead of plasmids. Using linear DNA molecules, i.e. PCR products, would expedite the process 
since the entire process could be done without cells and we could avoid laborious cloning steps. As a model system, we first repeated the experiments presented in Figure 6 with linear templates and observed that the linear DNA templates can successfully be expressed to complete the $n$-butanol biosynthesis pathway (Supplementary Fig. 9). Next, we chose to screen multifunctional enzymes that to our knowledge have never before used for $n$-butanol production. We selected four enzymes with proposed $\mathrm{Hbd}$ and $\mathrm{Crt}$ functionalities that were identified by NCBI-BLAST searches. By preparing reactions with three different enzyme mixtures (mixed extracts with overexpressed enzymes prior to lysis) (1) without $\mathrm{Hbd}$, (2) without Crt, and (3) without $\mathrm{Hbd}$ and $\mathrm{Crt}$, we could characterize each enzyme variant by their ability to perform each enzymatic function. We discovered that each of these enzymes could activate $n$-butanol synthesis, and the proposed Hbdcrt6 from Sulfolobus acidocaldarius only had Hbd functionality (Figure 6B). The ability to use linear DNA templates for CFPS-ME makes possible the ability to rapidly screen individual and sets of enzymes completely in vitro. Here, we used this approach to parse out individual functionalities of multi-functional enzymes.

\section{Discussion}

In this study, we developed a new cell-free framework for prototyping biosynthetic pathways and screening enzymes. In one scenario, we overexpress individual pathway components in cells, lyse these cells, and mix and match lysates in cell-free cocktails to study biochemical pathway performance. In a distinct thrust from typical in vitro systems, our approach allows us to study heterologous pathways in the 
context of native metabolism. In another scenario, we bypass in vivo expression altogether by using CFPS to enrich lysates with different enzymes for combinatorial assembly of different pathways. The combination of CFPS to express homologs of individual biosynthetic enzymes for studying pathway performance is also a distinction of our workflow. In addition, the use of linear PCR templates, which could be improved by DNA stability techniques (e.g., the addition of purified GamS protein) ${ }^{30}$, allows us to avoid in vivo cloning steps altogether. Our CFPS-ME approach should therefore be faster than conventional approaches to select enzymes and pathway designs in cells (hours instead of days/weeks), and enables parallelized pathway construction of combinatorial designs to accelerate DBT cycles.

A key conceptual innovation of our work is that the DBT unit can be cell-free lysates rather than genetic constructs. Engineering large biosynthetic systems composed of many genes in microbes remains challenging ${ }^{27}$. One of the many obstacles is simply how many different genetic designs with beneficial chances are feasible to make. Cell-free systems have already been shown to screen genetic designs to improve enzyme performance at a rapid rate $^{51}$. Our CFPS-ME framework should allow researchers to study more designs than previously possible by rapidly prototyping enzyme performance in vitro before putting designs into a host. As an example, a sixstep biosynthetic pathway testing 5 homologs for each enzymatic step would require testing of 15,625 pathway combinations. While this set of combinations exceeds typical pipelines pursued in cells today, our CFPS-ME system could leverage robotic or automated liquid-handling systems to access such design space.

The goal of this manuscript was to provide a new approach to building 
biosynthetic pathways in a modular fashion in vitro. Now achieved, we plan to optimize a large-scale fermentation process with the CFPS-ME approach in the future. Towards this goal, we additionally carried out experiments to show that protein expression in the cell-free system translates to the in vivo system. Specifically, we took all Ter homologs screened in vitro by CFPS-ME (Figure 6) and expressed them in whole cells in vivo. All but one of the Ter homolog proteins can be expressed in cells on a first pass (as determined by SDS-page expression, Supplementary Figure 10). These data show that protein expression in the cell-free system can translate to the in vivo system. Thus our approach holds promise for identifying good enzymes that can be expressed in cells, following a body of work that uses in vitro enzyme assays to identify enzymes with the best-performing biochemical characteristics for desired metabolic transformations prior to putting them into a host. For example, Liao and colleagues showed that in vitro reconstitution could be used to construct the non-oxidative glycolytic pathway prior to in vivo expression ${ }^{52}$, and Zhu et al. reconstituted the mevalonate pathway in vitro to study pathway kinetics before using the pathway in vivo for the production of farnesene ${ }^{53}$.

Our cell-free approach mimics the intracellular environment of $E$. coli, where endogenous glycolytic enzymes from the cell extract convert glucose to AcCoA. Thus, our platform enables many different biosynthetic pathways to be studied in the context of central metabolism with enhanced control inherent to in vitro systems. Here, we were able to increase $n$-butanol production by $\sim 200 \%$ of our initial starting conditions (up to $\sim 1.5 \mathrm{~g} \mathrm{l}^{-1}$ ) by simply testing the performance of different enzymes sets and adjusting the physicochemical environment. While it is be difficult to compare in a normalized fashion the in vitro process to the in vivo process, our results (given as final measured 
concentration) are higher than some published reports of $n$-butanol production in comparable genomically unmodified hosts (Supplementary Figure 11) $37,54-56$. However, Bond-Watts et al. notably reported titers of $4.6 \mathrm{~g} \mathrm{l}^{-1}$ in a genomically unmodified host by selecting a particular set of synergistic enzymes and taking advantage of their chemistries $^{18}$. Given the reasonable yields, we were curious as to how the CFPS-ME reactions would perform at increased scale. We thus performed additional experiments of increasing size reactions to give confidence in our quantitative yields. Specifically, the reaction volume of CFPS-ME reactions was scaled from 25 to $250 \mu \mathrm{L}$, an order of magnitude increase (Supplementary Figure 12). Our data shows that these reactions are scalable and are consistent with several previous works showing the ability of cellfree systems to scale linearly ${ }^{36,57-60}$.

Looking forward, specialty chemicals, natural products, and materials offer an extremely diverse set of compounds with a seemingly infinite set of structures and bioactivities. Our CFPS-ME approach offers a new discovery pipeline to leverage advances in DNA sequencing and DNA synthesis to optimize biosynthetic pathways, discover new enzymes, and test new hypotheses. Because it is an open system, cellfree reactors can be readily interrogated for intermediate product formation, such as by the on-line, high speed LC/MS approaches used by Panke and colleagues for optimization of glycolysis in cell-free extracts ${ }^{61}$. Cell-free systems in tandem with highend metabolomics could offer a high degree of flexibility to model the kinetics and stability of individual enzymes, measure metabolite fluxes in multistep pathways, and experimentally isolate many other parameters confounded in living organisms. This has potential to speed up metabolic engineering DBT cycles. 


\section{Acknowledgements}

This work is funded by the DARPA Program (D14PC00005/0001). Additional support was from the David and Lucille Packard Foundation (to M.C.J.). A.S.K. is an NSF Graduate Fellow.

\section{Author Contributions}

A.S.K. and M.C.J. conceived and designed the experiments. A.S.K. performed all of the experimental work. A.S.K. and M.C.J. wrote the manuscript.

\section{Competing Financial Interests}

The authors declare no competing financial interests. 


\section{References}

1 Bornscheuer, U. T. et al. Engineering the third wave of biocatalysis. Nature 485, 185-194, doi:10.1038/nature11117 (2012).

2 Fritz, B. R., Timmerman, L. E., Daringer, N. M., Leonard, J. N. \& Jewett, M. C. Biology by design: from top to bottom and back. Journal of biomedicine \& biotechnology 2010, 232016, doi:10.1155/2010/232016 (2010).

3 Curran, K. A. \& Alper, H. S. Expanding the chemical palate of cells by combining systems biology and metabolic engineering. Metabolic engineering 14, 289-297, doi:10.1016/j.ymben.2012.04.006 (2012).

4 Rollié, S., Mangold, M. \& Sundmacher, K. Designing biological systems: Systems Engineering meets Synthetic Biology. Chemical Engineering Science 69, 1-29, doi:10.1016/j.ces.2011.10.068 (2012).

5 Erickson, B., Nelson \& Winters, P. Perspective on opportunities in industrial biotechnology in renewable chemicals. Biotechnology journal 7, 176-185, doi:10.1002/biot.201100069 (2012).

6 Nielsen, J. et al. Engineering synergy in biotechnology. Nature chemical biology 10, 319-322, doi:10.1038/nchembio.1519 (2014).

7 Demain, A. L. Importance of microbial natural products and the need to revitalize their discovery. Journal of industrial microbiology \& biotechnology 41, 185-201, doi:10.1007/s10295-013-1325-z (2014).

8 Harvey, A. L., Edrada-Ebel, R. \& Quinn, R. J. The re-emergence of natural products for drug discovery in the genomics era. Nature reviews. Drug discovery 14, 111-129, doi:10.1038/nrd4510 (2015).

9 Kern, A., Tilley, E., Hunter, I. S., Legisa, M. \& Glieder, A. Engineering primary metabolic pathways of industrial micro-organisms. Journal of biotechnology 129, 6-29, doi:10.1016/j.jbiotec.2006.11.021 (2007).

10 Nielsen, J. Metabolic engineering. Applied Microbiology and Biotechnology 55, 263-283, doi:10.1007/s002530000511 (2001).

11 Hodgman, C. E. \& Jewett, M. C. Cell-free synthetic biology: thinking outside the cell. Metabolic engineering 14, 261-269, doi:10.1016/j.ymben.2011.09.002 (2012).

12 Kwok, R. Five hard truths for synthetic biology. Nature 463, 288-290, doi:10.1038/463288a (2010).

13 Green, E. M. Fermentative production of butanol--the industrial perspective. Current opinion in biotechnology 22, 337-343, doi:10.1016/j.copbio.2011.02.004 (2011).

14 Lutke-Eversloh, T. \& Bahl, H. Metabolic engineering of Clostridium acetobutylicum: recent advances to improve butanol production. Current opinion in biotechnology 22, 634-647, doi:10.1016/j.copbio.2011.01.011 (2011).

15 Atsumi, S. et al. Metabolic engineering of Escherichia coli for 1-butanol production. Metabolic engineering 10, 305-311, doi:10.1016/j.ymben.2007.08.003 (2008).

16 Steen, E. J. et al. Metabolic engineering of Saccharomyces cerevisiae for the production of n-butanol. Microbial cell factories 7, 36, doi:10.1186/1475-2859-736 (2008). 
17 Shen, C. R. et al. Driving forces enable high-titer anaerobic 1-butanol synthesis in Escherichia coli. Applied and environmental microbiology 77, 2905-2915, doi:10.1128/AEM.03034-10 (2011).

18 Bond-Watts, B. B., Bellerose, R. J. \& Chang, M. C. Enzyme mechanism as a kinetic control element for designing synthetic biofuel pathways. Nature chemical biology 7, 222-227, doi:10.1038/nchembio.537 (2011).

19 Dong, H. et al. Engineering Escherichia coli Cell Factories for n-Butanol Production. Advances in biochemical engineering/biotechnology, doi:10.1007/10_2015_306 (2015).

20 Keasling, J. D. Manufacturing molecules through metabolic engineering. Science 330, 1355-1358, doi:10.1126/science.1193990 (2010).

21 Keasling, J. D. Synthetic biology and the development of tools for metabolic engineering. Metabolic engineering 14, 189-195, doi:10.1016/j.ymben.2012.01.004 (2012).

22 Jensen, M. K. \& Keasling, J. D. Recent applications of synthetic biology tools for yeast metabolic engineering. FEMS Yeast Res, doi:10.1111/1567-1364.12185 (2014).

23 Dai, Z. \& Nielsen, J. Advancing metabolic engineering through systems biology of industrial microorganisms. Current opinion in biotechnology 36, 8-15, doi:10.1016/j.copbio.2015.08.006 (2015).

24 Lee, S. Y. \& Kim, H. U. Systems strategies for developing industrial microbial strains. Nat Biotechnol 33, 1061-1072, doi:10.1038/nbt.3365 (2015).

25 Lee, J. W. et al. Systems metabolic engineering of microorganisms for natural and non-natural chemicals. Nature chemical biology 8, 536-546, doi:10.1038/nchembio.970 (2012).

26 Yadav, V. G., De Mey, M., Giaw Lim, C., Kumaran Ajikumar, P. \& Stephanopoulos, $G$. The future of metabolic engineering and synthetic biology: Towards a systematic practice. Metabolic engineering 14, 233-241, doi:10.1016/j.ymben.2012.02.001 (2012).

27 Smanski, M. J. et al. Functional optimization of gene clusters by combinatorial design and assembly. Nat Biotechnol 32, 1241-1249, doi:10.1038/nbt.3063 (2014).

28 Boyle, P. M. \& Silver, P. A. Parts plus pipes: synthetic biology approaches to metabolic engineering. Metabolic engineering 14, 223-232, doi:10.1016/j.ymben.2011.10.003 (2012).

29 Carlson, E. D., Gan, R., Hodgman, C. E. \& Jewett, M. C. Cell-free protein synthesis: applications come of age. Biotechnology advances 30, 1185-1194, doi:10.1016/j.biotechadv.2011.09.016 (2012).

30 Sun, Z. Z., Yeung, E., Hayes, C. A., Noireaux, V. \& Murray, R. M. Linear DNA for rapid prototyping of synthetic biological circuits in an Escherichia coli based TXTL cell-free system. ACS synthetic biology 3, 387-397, doi:10.1021/sb400131a (2014).

31 Siegal-Gaskins, D., Tuza, Z. A., Kim, J., Noireaux, V. \& Murray, R. M. Gene circuit performance characterization and resource usage in a cell-free "breadboard". ACS synthetic biology 3, 416-425, doi:10.1021/sb400203p (2014). 
32 Dudley, Q. M., Karim, A. S. \& Jewett, M. C. Cell-free metabolic engineering: biomanufacturing beyond the cell. Biotechnology journal 10, 69-82, doi:10.1002/biot.201400330 (2015).

33 Zhang, Y. H. Production of biofuels and biochemicals by in vitro synthetic biosystems: Opportunities and challenges. Biotechnology advances 33, 14671483, doi:10.1016/j.biotechadv.2014.10.009 (2015).

34 You, C. \& Zhang, Y. H. Cell-free biosystems for biomanufacturing. Advances in biochemical engineering/biotechnology 131, 89-119, doi:10.1007/10_2012_159 (2013).

35 Guterl, J. K. et al. Cell-free metabolic engineering: production of chemicals by minimized reaction cascades. ChemSusChem 5, 2165-2172, doi:10.1002/cssc.201200365 (2012).

36 Kay, J. E. \& Jewett, M. C. Lysate of engineered Escherichia coli supports highlevel conversion of glucose to 2,3-butanediol. Metabolic engineering 32, 133-142, doi:10.1016/j.ymben.2015.09.015 (2015).

37 Krutsakorn, B. et al. In vitro production of n-butanol from glucose. Metabolic engineering 20, 84-91, doi:10.1016/j.ymben.2013.09.006 (2013).

38 Ninh, P. H., Honda, K., Sakai, T., Okano, K. \& Ohtake, H. Assembly and multiple gene expression of thermophilic enzymes in Escherichia coli for in vitro metabolic engineering. Biotechnol Bioeng 112, 189-196, doi:10.1002/bit.25338 (2015).

39 Welch, P. \& Scopes, R. K. Studies on cell-free metabolism: Ethanol production by a yeast glycolytic system reconstituted from purified enzymes. Journal of biotechnology 2, 257-273, doi:10.1016/0168-1656(85)90029-x (1985).

40 Swartz, J. R. Transforming biochemical engineering with cell-free biology. AlChE Journal 58, 5-13, doi:10.1002/aic.13701 (2012).

41 Dodevski, I., Markou, G. C. \& Sarkar, C. A. Conceptual and methodological advances in cell-free directed evolution. Curr Opin Struct Biol 33, 1-7, doi:10.1016/j.sbi.2015.04.008 (2015).

42 Henrich, E., Hein, C., Dotsch, V. \& Bernhard, F. Membrane protein production in Escherichia coli cell-free lysates. FEBS Lett 589, 1713-1722, doi:10.1016/j.febslet.2015.04.045 (2015).

43 Zemella, A., Thoring, L., Hoffmeister, C. \& Kubick, S. Cell-Free Protein Synthesis: Pros and Cons of Prokaryotic and Eukaryotic Systems. Chembiochem 16, 2420-2431, doi:10.1002/cbic.201500340 (2015).

44 Noireaux, V., Bar-Ziv, R. \& Libchaber, A. Principles of cell-free genetic circuit assembly. Proc Natl Acad Sci U S A 100, 12672-12677, doi:10.1073/pnas.2135496100 (2003).

45 Goshima, N. et al. Human protein factory for converting the transcriptome into an in vitro-expressed proteome. Nature Methods 5, 1011-1017, doi:10.1038/nmeth.1273 (2008).

46 Jewett, M. C., Calhoun, K. A., Voloshin, A., Wuu, J. J. \& Swartz, J. R. An integrated cell-free metabolic platform for protein production and synthetic biology. Mol Syst Biol 4, 220, doi:10.1038/msb.2008.57 (2008).

47 Jewett, M. C. \& Swartz, J. R. Mimicking the Escherichia coli cytoplasmic environment activates long-lived and efficient cell-free protein synthesis. Biotechnol Bioeng 86, 19-26, doi:10.1002/bit.20026 (2004). 
48 Korman, T. P. et al. A synthetic biochemistry system for the in vitro production of isoprene from glycolysis intermediates. Protein Sci 23, 576-585, doi:10.1002/pro.2436 (2014).

49 Record, M. T., Courtenay, E. S., Cayley, S. \& Guttman, H. J. Biophysical compensation mechanisms buffering E. coli protein-nucleic acid interactions against changing environments. Trends in Biochemical Sciences 23, 190-194, doi:10.1016/s0968-0004(98)01207-9 (1998).

50 Jewett, M. C., Fritz, B. R., Timmerman, L. E. \& Church, G. M. In vitro integration of ribosomal RNA synthesis, ribosome assembly, and translation. Mol Syst Biol 9, 678, doi:10.1038/msb.2013.31 (2013).

51 Daugherty, A. B., Govindarajan, S. \& Lutz, S. Improved biocatalysts from a synthetic circular permutation library of the flavin-dependent oxidoreductase old yellow enzyme. J Am Chem Soc 135, 14425-14432, doi:10.1021/ja4074886 (2013).

52 Bogorad, I. W., Lin, T. S. \& Liao, J. C. Synthetic non-oxidative glycolysis enables complete carbon conservation. Nature 502, 693-697, doi:10.1038/nature12575 (2013).

53 Zhu, F. et al. In vitro reconstitution of mevalonate pathway and targeted engineering of farnesene overproduction in Escherichia coli. Biotechnol Bioeng 111, 1396-1405, doi:10.1002/bit.25198 (2014).

54 Gulevich, A. Y., Skorokhodova, A. Y., Sukhozhenko, A. V., Shakulov, R. S. \& Debabov, V. G. Metabolic engineering of Escherichia coli for 1-butanol biosynthesis through the inverted aerobic fatty acid beta-oxidation pathway. Biotechnol Lett 34, 463-469, doi:10.1007/s10529-011-0797-z (2012).

55 Nielsen, D. R. et al. Engineering alternative butanol production platforms in heterologous bacteria. Metabolic engineering 11, 262-273, doi:10.1016/j.ymben.2009.05.003 (2009).

56 Inui, M. et al. Expression of Clostridium acetobutylicum butanol synthetic genes in Escherichia coli. Appl Microbiol Biotechnol 77, 1305-1316, doi:10.1007/s00253-007-1257-5 (2008).

57 Yin, G. et al. Aglycosylated antibodies and antibody fragments produced in a scalable in vitro transcription-translation system. MAbs 4, 217-225, doi:10.4161/mabs.4.2.19202 (2012).

58 Zawada, J. F. et al. Microscale to manufacturing scale-up of cell-free cytokine production--a new approach for shortening protein production development timelines. Biotechnol Bioeng 108, 1570-1578, doi:10.1002/bit.23103 (2011).

59 Voloshin, A. M. \& Swartz, J. R. Efficient and scalable method for scaling up cell free protein synthesis in batch mode. Biotechnol Bioeng 91, 516-521, doi:10.1002/bit.20528 (2005).

60 Hong, S. H. et al. Improving cell-free protein synthesis through genome engineering of Escherichia coli lacking release factor 1. Chembiochem 16, 844853, doi:10.1002/cbic.201402708 (2015).

61 Bujara, M., Schumperli, M., Pellaux, R., Heinemann, M. \& Panke, S. Optimization of a blueprint for in vitro glycolysis by metabolic real-time analysis. Nat Chem Biol 7, 271-277, doi:10.1038/nchembio.541 (2011). 